TI 2018-090/VII

Tinbergen Institute Discussion Paper

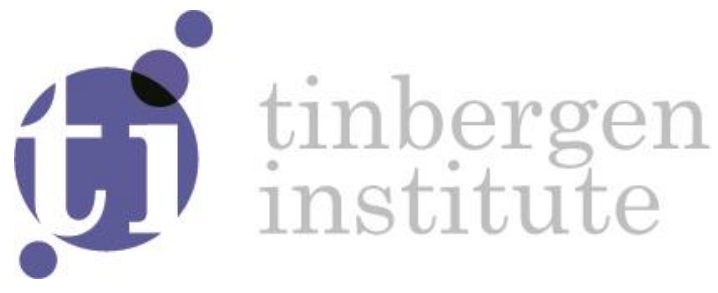

\title{
Insuring product markets
}

\author{
Jeroen (J.) Hinloopen ${ }^{1}$ \\ Lting Zhou ${ }^{2}$
}

${ }^{1}$ UVA

2 Tinbergen Institute 
Tinbergen Institute is the graduate school and research institute in economics of Erasmus University Rotterdam, the University of Amsterdam and VU University Amsterdam.

Contact: discussionpapers@tinbergen.nl

More TI discussion papers can be downloaded at http://www.tinbergen.nl

Tinbergen Institute has two locations:

Tinbergen Institute Amsterdam

Gustav Mahlerplein 117

1082 MS Amsterdam

The Netherlands

Tel.: +31(0)205984580

Tinbergen Institute Rotterdam

Burg. Oudlaan 50

3062 PA Rotterdam

The Netherlands

Tel.: +31(0)10408 8900 


\title{
Insuring product markets*
}

\author{
Jeroen Hinloopen ${ }^{\dagger}$ and Liting Zhou ${ }^{\ddagger}$
}

November 11, 2018

\begin{abstract}
We formally link insurance markets with product markets and identify a demand effect of insurance: if risk-averse consumers can buy insurance against possible product failure, there will be some additional consumers that buy the product because they can also purchase protection. The concomitant upward pressure on price is further fueled by those consumers that have a higher willingness to pay if they can also buy insurance. But a higher price causes those consumers to leave the market that would have bought the product absent insurance. Introducing insurance thus has an ambiguous effect on price, consumers' surplus, and total surplus.
\end{abstract}

Key words: product failure, insured loss, insurance, product markets, demand effect of insurance

JEL Classification: D21, D43, L13

\footnotetext{
*We thank Wim Röst for bringing the influence of independent insurers on the workings of product markets to our attention. Thanks are further due to Maarten Janssen, Stephen Martin, Adriaan Soetevent, Jarig van Sinderen, and to seminar participants at the Tinbergen Institute, at the University of Amsterdam, and at Purdue University. The usual disclaimer applies.

${ }^{\dagger}$ Corresponding author. CPB Netherlands Bureau for Economic Policy Analysis and University of Amsterdam; J.Hinloopen@uva.nl.

¥Tinbergen Institute; L.Zhou@tinbergen.nl.
} 


\section{Introduction}

In the U.S. in 2017 the top ten leading writers of private passenger auto insurance jointly received more than 166 billion U.S. dollar in insurance premia (Statista, 2018). Automobile insurance cover the cost to redress potential losses related to vehicle operation, including injuries to drivers, passengers and bystanders, vehicle damage, and theft. These various costs correspond to prices of the products and/or services needed to redress potential losses of the insured. Indeed, this correspondence between cost and price applies to virtually any insurance policy; insured loss sizes are market prices of products and/or services that are needed to redress the insured loss. In spite of its wide applicability, it is still an open question to what extent the possibility to purchase insurance from an independent insurer affects the equilibrium on markets that provide the concomitant products and/or processes. In this paper we set a first step in closing this gap in the literature and examine the influence of insurance in a market where consumers can purchase a product that possibly fails.

Risk spreading through voluntary insurance is generally perceived to benefit both insurers and insurees (Mass-Colell et al., 1995). A crucial assumption for this premise to hold is that the insured risk is immune to the possibility to buy protection. For instance, moral hazard can increase an insured risk, notably the probability that a loss occurs. ${ }^{1}$ We ignore all aspects of asymmetric information and assume a fixed loss probability. Rather, we observe that it is difficult to maintain a fixed loss size if it is understood that the size of the loss corresponds to the market price of the product needed to redress the loss. ${ }^{2}$

To date, the literature has exclusively considered the situation where insurance against product failure is offered by the product manufacturer in the form of a warranty or guarantee. ${ }^{3}$ But the incentives that rule the decisions of an independent insurer differ

\footnotetext{
${ }^{1}$ See the seminal paper by Pauly (1974); Dunham (2003) finds that fleet vehicles, which are typically not driven by their owners (that is, by those that bear all the cost of care abuse and neglect) "depreciate approximately ten to thirteen percent faster per-year than owner-driven vehicles."

${ }^{2}$ A small literature examines insurers' incentives to influence the risk size, either through the loss probability (e.g. Schlesinger and Venezian, 1986) or the loss size (e.g. Schlezinger and Venezian, 1990), without, however, specifying the origins of the loss size.

${ }^{3}$ Heal (1977) shows that a risk-neutral seller will offer a complete guarantee (in the sense that it covers full product replacement costs). Spence (1977) and Grossman (1981) interpret warranties as a signal (see Boulding and Kirmani (1993) for related experimental tests) whereas Cooper and Ross (1985) link the extent of warranty protection to product quality (see also Lutz, 1989).
} 
from those of the manufacturer. For instance, an independent insurer would welcome high(er) prices as that makes it more likely that (risk averse) consumers will also purchase protection. We thus consider the case where insurance is offered by an independent insurer to consumers that can buy a product that possibly fails in the sense of Spence (1977): with some probability the product does not yield any utility. ${ }^{4}$ In particular, we examine the effect of insurance policies that specify to replace the product in case of failure, and that can be purchased together with the product from an independent insurer.

In so doing we identify a demand effect of insurance: some consumers buy the product only because they can also purchase protection against product failure. This demandeffect of insurance is an increase in trade that is always to the benefit of both consumers and the supply side of the market, provided that the product price does not change in response to the possibility to purchase protection.

However, the additional demand puts upward pressure on price, which is further fueled by the subset of consumers that would have bought the product absent protection but that have a higher willingness to pay for purchases for which they can also buy insurance. ${ }^{5}$ Yet, the price effect of insurance is ambiguous because some of the consumers that buy the product for the pre-insurance price and that will not buy insurance, will not buy the product for a higher price. As a result, consumers will, or will not, benefit from the possibility to purchase protection against possible product failure if the price is allowed to respond the demand effect of insurance. Although producers' surplus always increases if insurance is offered by an independent insurer, this is not necessarily the case for consumers' surplus and total surplus.

\footnotetext{
${ }^{4}$ This definition applies to both products and services. Throughout the paper we speak of 'product failure', which is understood to include failure of services.

${ }^{5}$ For the new car market, Guajardo et al. (2016) document the relation between buyer protection and buyers' willingness to pay. They find that "...the effect on consumer utility of a $1 \%$ price decrease is equivalent, all else being equal, to increasing product quality by $2.2 \%$, and is in turn equivalent to increasing the warranty length by $8 \%$.", which illustrates the interdependence between the possibility to purchase insurance and the willingness to pay for the underlying product.
} 


\section{Buying under uncertainty}

Consider a set of consumers $\Xi$. Each consumer $i \in \Xi$ is endowed with initial wealth $Y$ and has to decide about a purchase that yields utility $s$ and that costs $p$. A consumer that refrains from buying has utility $U_{i}(Y)$. Consumers are assumed to be risk averse: $U^{\prime}>0$, $U^{\prime \prime} \leq 0$. The purchase carries a risk in the sense of Spence (1977): with probability $\varphi \in(0,1)$ it does not yield any utility; it 'fails'. Accordingly, a purchase yields expected utility:

$$
E U_{i}(Y-p ; s)=U_{i}(Y-p)+(1-\varphi) s
$$

Consumer $i$ buys the product if, and only if, $E U_{i}(Y-p ; s)>U_{i}(Y)$.

Next, we introduce an insurance market that offers a policy against possible product failure at premium $R>0$. Utility from buying the product with insurance is:

$$
U_{i}(Y-p-R ; s)=U_{i}(Y-p-R)+s
$$

That is, the insurance policy guarantees surplus $s$. This leaves the insurer with an expected cost of $\varphi p /(1-\varphi)$ per insured consumer, assuming product failure and concomitant repeat purchases (by the insurer) to materialize instantaneously.

Figure 1 illustrates the purchasing decision of a consumer that buys the product with insurance rather than without insurance. The certainty equivalent of buying the product is $C E_{i}=U_{i}^{-1}\left[U_{i}(Y-p)+(1-\varphi) s\right]$, implying that the maximum premium a consumer is willing to pay equals $R^{\max }=U_{i}^{-1}\left(U_{i}(Y-p)+s\right)-C E$. The concomitant risk premium equals $\pi=\varphi(Y-p)+(1-\varphi) U_{i}^{-1}\left(U_{i}(Y-p)+s\right)-C E$.

The next lemma formally establishes that an insurance policy will be offered by an independent insurer absent barriers to entry to the insurance market. ${ }^{6}$

Lemma 1 Risk premium $\pi$ is positive.

\section{Demand effect of insurance}

Consumers thus buy the product with insurance, without insurance, or not at all. This gives rise to three different indifference curves, each separating two purchasing decisions

\footnotetext{
${ }^{6}$ All proofs are in the Appendix
} 


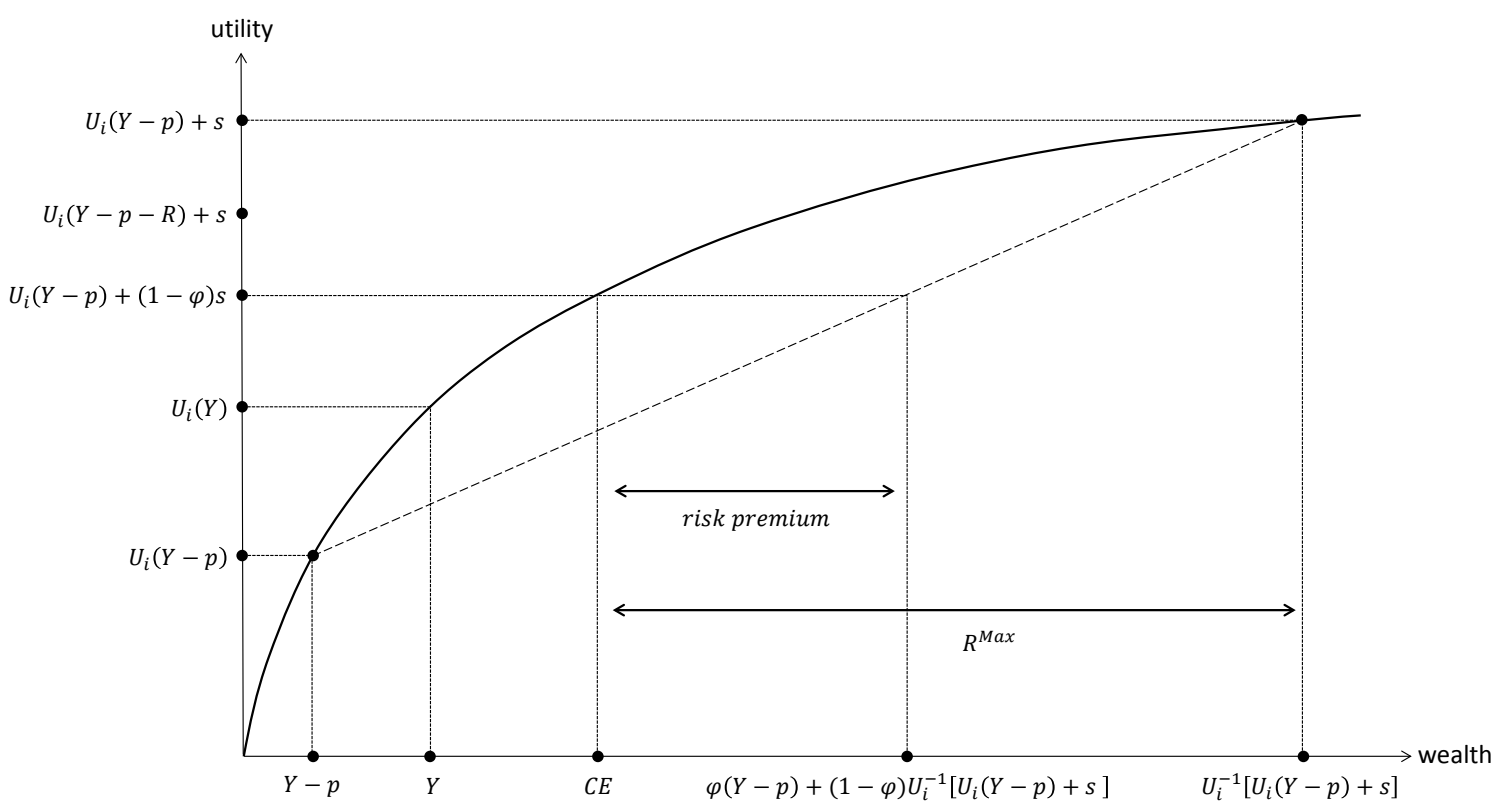

Figure 1: Purchasing decision of a consumer that buys the product and insurance, with $C E_{i}=U_{i}^{-1}\left[U_{i}(Y-p)+(1-\varphi) s\right]$ being the certainty equivalent of the purchase.

in $s-\varphi$-space. The first curve distinguishes between consumers that buy with insurance and those that buy without insurance, $U_{i}(Y-p-R)+s=U_{i}(Y-p)+(1-\varphi) s$, and reads as:

$$
s=\frac{U_{i}(Y-p)-U_{i}(Y-p-R)}{\varphi}=I C_{1} .
$$

The second curve separates consumers that do not buy from those that buy without insurance, $U_{i}(Y-p)+(1-\varphi) s=U_{i}(Y)$, and is given by:

$$
s=\frac{U_{i}(Y)-U_{i}(Y-p)}{1-\varphi}=I C_{2} .
$$

Finally, comparing consumers that do not buy with those that buy with insurance, $U_{i}(Y)=U_{i}(Y-p-R)+s$, yields:

$$
s=U_{i}(Y)-U_{i}(Y-p-R)=I C_{3} .
$$

The three indifference curves divide consumer set $\Xi$ into six mutually exclusive groups: $\Xi=\xi_{1} \cup \ldots \cup \xi_{6}$ with $\xi_{i} \cap \xi_{j}=\emptyset \forall i \neq j$, see Figure 2. Each consumer $i \in \xi_{1}$ buys the product, but rather with insurance than without insurance:

$$
\xi_{1}=\sum_{i} I\left[U_{i}(Y-p-R ; s)>E U_{i}(Y-p ; s)>U_{i}(Y)\right]
$$




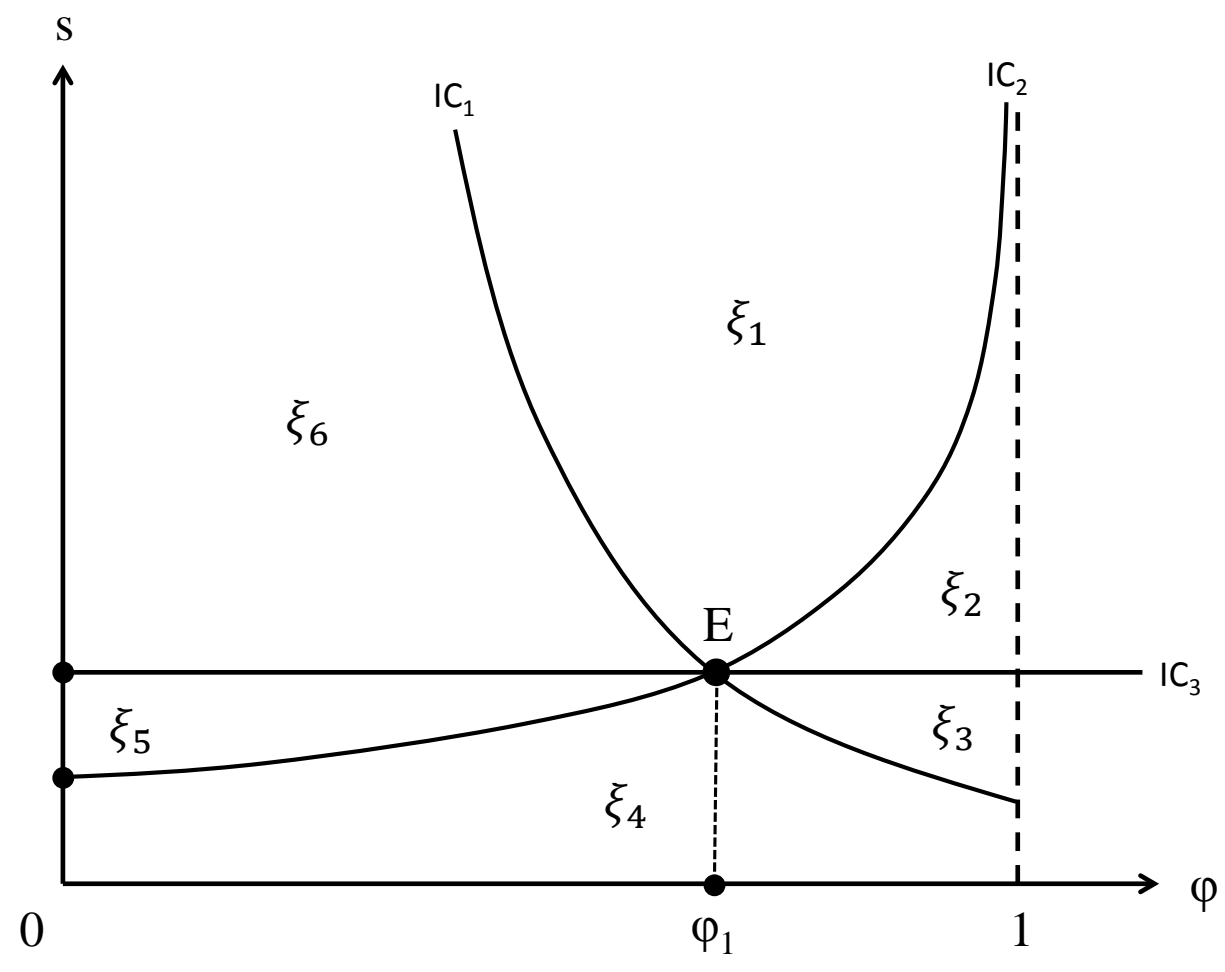

Figure 2: Consumer types, with $\xi_{1}: U_{i}(Y-p-R)+s>U_{i}(Y-p)+(1-\varphi) s>U_{i}(Y)$, $\xi_{2}: U_{i}(Y-p-R)+s>U_{i}(Y)>U_{i}(Y-p)+(1-\varphi) s, \xi_{3}: U_{i}(Y)>U_{i}(Y-p-R)+s>U_{i}(Y-$ $p)+(1-\varphi) s, \xi_{4}: U_{i}(Y)>U_{i}(Y-p)+(1-\varphi) s>U_{i}(Y-p-R)+s, \xi_{5}: U_{i}(Y-p)+(1-\varphi) s>$ $U_{i}(Y)>U_{i}(Y-p-R)+s$, and $\xi_{6}: U_{i}(Y-p)+(1-\varphi) s>U_{i}(Y-p-R)+s>U_{i}(Y)$, where $I C_{1}=U_{i}(Y-p) /\left(\varphi U_{i}(Y-p-R)\right), I C_{2}=\left(U_{i}(Y)-U_{i}(Y-p)\right) /(1-\varphi)$, and $I C_{3}=U_{i}(Y)-U_{i}(Y-p-R)$. 
These consumers have a higher willingness to pay if insurance is offered. Consumers in the second group also buy the product, but they do so because they can also buy insurance:

$$
\xi_{2}=\sum_{i} I\left[U_{i}(Y-p-R ; s)>U_{i}(Y)>E U_{i}(Y-p ; s)\right]
$$

The third group of consumers does not buy the product, although they attach greater value to a purchase with insurance than without insurance:

$$
\xi_{3}=\sum_{i} I\left[U_{i}(Y)>U_{i}(Y-p-R ; s)>E U_{i}(Y-p ; s)\right]
$$

whereas the fourth consumer group also does not buy the product, but would not buy insurance in case of a purchase:

$$
\xi_{4}=\sum_{i} I\left[U_{i}(Y)>E U_{i}(Y-p ; s)>U_{i}(Y-p-R ; s)\right]
$$

The fifth consumer group comprises all consumers that buy the product, but that would not buy the product with insurance:

$$
\xi_{5}=\sum_{i} I\left[E U_{i}(Y-p ; s)>U_{i}(Y)>U_{i}(Y-p-R ; s)\right]
$$

Consumers in the final group also buy the product without insurance, but would rather buy with insurance than not buying at all:

$$
\xi_{6}=\sum_{i} I\left[E U_{i}(Y-p ; s)>U_{i}(Y-p-R ; s)>U_{i}(Y)\right]
$$

Absent insurance, consumers in area $\xi_{2}$ do not buy the product and consumers in area $\xi_{1}$ have a higher willingness to pay if they can also purchase protection. This comprises our central result; the identification of a demand effect of insurance.

Theorem 1 In an economy with risk-averse consumers that can buy a product that possibly fails, introduction of an insurance policy by an independent insurer that offers protection against product failure (i) expands total demand, and (ii) increases the willingnessto-pay for part of the existing demand.

Theorem 1 does not hinge on any assumption about the product market or the insurance market other than assuming that there are no prohibitively high entry barriers to 
either market. Indeed, the demand effect of insurance is independent of the price in the product market and the concomitant insurance premium.

According to Theorem 1, introduction of the possibility to purchase insurance induces more consumers to buy the product at the prevailing price. Therefore:

Corollary 1 In an economy with risk-averse consumers that can buy a product that possibly fails, introduction of an insurance policy by an independent insurer that offers protection against product failure while not allowing for a price adjustment, increases consumers' surplus.

Absent insurance, the product supplier earns:

$$
\Pi^{N I}=p\left(\xi_{1}+\xi_{5}+\xi_{6}\right)
$$

With insurance these profits equal:

$$
\Pi^{I N}=p\left(\xi_{1}+\xi_{2}+\xi_{5}+\xi_{6}\right)(1+\varphi) .
$$

If anything, the demand effect of insurance will not reduce the product supplier's profits. In combination with Lemma 1 and Corollary 1 this implies:

Corollary 2 In an economy with risk-averse consumers that can buy a product that possibly fails, introduction of an insurance policy by an independent insurer that offers protection against product failure while not allowing for a price adjustment, increases producers' surplus and total surplus.

In addition to the traditional welfare-enhancing effect of risk spreading through voluntary insurance, the demand effect of insurance enhances welfare as well. It identifies an increase in trade that is to the benefit of both consumers and the supply side of the market, provided that the product price does not change in response to the possibility to purchase protection.

\section{Price effect of insurance}

If the product is supplied by a perfectly competitive market, the demand effect of insurance will trigger additional supply without affecting the price of the product. For all other market structures the price can adjust to absorb the demand-effect of insurance. 
The profit-maximizing response to the demand effect of insurance is ruled by the reaction of consumers as partitioned in Figure 2 to price adjustments. For instance, a higher price might induce some consumers to buy the product with insurance rather than without protection. It could also induce some consumers not to buy the product (anymore).

Absent insurance, the optimal price $p^{N I}$ maximizes (12):

$$
\xi_{1}\left(p^{N I}\right)+\xi_{5}\left(p^{N I}\right)+\xi_{6}\left(p^{N I}\right)+p^{N I}\left(\xi_{1}^{\prime}+\xi_{5}^{\prime}+\xi_{6}^{\prime}\right) \equiv 0,
$$

with $\xi_{i}^{\prime}=d \xi_{i} / d p$. Likewise, $p^{I N}$ follows from:

$$
\xi_{1}\left(p^{I N}\right)+\xi_{2}\left(p^{I N}\right)+\xi_{5}\left(p^{I N}\right)+\xi_{6}\left(p^{I N}\right)+p^{I N}\left(\xi_{1}^{\prime}+\xi_{2}^{\prime}+\xi_{5}^{\prime}+\xi_{6}^{\prime}\right) \equiv 0
$$

Comparing (14) with (15) reveals the ambiguity of the price effect of insurance:

Theorem 2 In an economy with risk-averse consumers that can buy a product that possibly fails, introduction of an insurance policy by an independent insurer that offers protection against product failure has an ambiguous effect on price.

Theorem 1 and Theorem 2 jointly imply that some consumers will benefit from the possibility to purchase protection against possible product failure, while others stand to loose. This conclusion in combination with Corollary 2 logically extends to total surplus:

Corollary 3 In an economy with risk-averse consumers that can buy a product that possibly fails, introduction of an insurance policy by an independent insurer that offers protection against product failure has an ambiguous effect on consumers' surplus and on total surplus.

\section{Conclusion}

In this paper we have formally linked insurance markets with product markets, which leads us to identify a demand-effect of insurance: some consumers will buy the product only because they can also purchase insurance against product failure. This creates upward pressure on the market price, which is further fueled by those consumers that buy the 
product rather with insurance than without. At the same time, there are consumers that buy the product without protection, and only for the pre-insurance price; they will leave the market if price increases. As a result, the price effect of insurance ambiguous; if price is allowed to absorb the demand-effect of insurance it might increase, decrease, or not change at all. Hence, although introducing an independent insurer always increases producers' surplus, the effect on consumers' surplus and total surplus is also ambiguous.

We can think of several directions of future research, including empirical studies of markets that supply products to possibly insured consumers, or an analysis of the insurer's most preferred price. Indeed, as Hinloopen (2009) has shown, monopoly insurers have an incentive to inflate loss sizes as that yields a more than proportional increase in the risk premium.

\section{References}

[1] Boulding, W. and A. Kirmani (1993). "A consumer-side experimental investigation of signaling theory: Do consumers perceive warranties as signals of quality?", Journal of Consumer Research 20(1): 111 - 123.

[2] Cooper, R. and T. W. Ross (1985). "Product warranties and double moral hazard", RAND Journal of Economics 16(1): 103 - 113.

[3] Dunham, W. R. (2003). "Moral hazard and the market for used automobiles", Review of Industrial Organization 23: 65 - 83.

[4] Grossman, S. J. (1981). "The informational role of warranties and private disclosure about product quality", Journal of Law and Economics 24(3): 461 - 483.

[5] Guajardo, J. A., M. A. Cohen and S. Netessine (2016). "Service competition and product quality in the U.S. automobile industry", Management Science 62(7): 1860 1877.

[6] Heal, G. (1977). "Guarantees and risk-sharing", Review of Economic Studies 44(3): $549-560$. 
[7] Hinloopen, J. (2009). "Verzekerde marktmacht", Inaugural Lecture Series 370, Amsterdam: Amsterdam University Press.

[8] Lutz, N. A. (1989). "Warranties as signals under consumer moral hazard", RAND Journal of Economics 20(2): 239 - 255.

[9] Mass-Colell, A., M. D. Whinston, and J. R. Green (1995) Microeconomic Theory, New York and Oxford: Oxford University Press.

[10] Pauly, M. V. (1974). "Overinsurance and public provision of insurance: the roles of moral hazard and adverse selection", The Quarterly Journal of Economics 88 (1): 44 -62 .

[11] Schlesinger, H. and E. C. Venezian (1986). "Insurance markets with loss-prevention activity: profits, market structure, and consumer welfare", RAND Journal of Economics 17(2): 227 - 238 .

[12] Schlesinger, H. and E. C. Venezian (1990). Ex ante loss control by insurers: Public interest for higher profit, Journal of Financial Services Research 4(2): 83 - 92.

[13] Spence, M. (1977). "Misperceptions, product failure and producer liability", Review of Economic Studies 44(3): 561 - 572.

[14] Statistica (2018). https://www.statista.com/statistics/186513/top-writers-ofus-private-passenger-auto-insurance-by-premiums-written/, website consulted on November 5, 2018. 


\section{Appendix - Proofs}

\subsection{Proof of Lemma 1}

Let $\pi=A-C E . U_{i}(A)=U_{i}\left(\varphi(Y-p)+(1-\varphi) U_{i}^{-1}\left(U_{i}(Y-p)+s\right)\right)>\varphi U_{i}(Y-p)+(1-\varphi) s=$ $U_{i}(C E) \Leftrightarrow A>C E \Leftrightarrow \pi>0$.

\subsection{Proof of Theorem 1}

(i) $\xi_{2}$ is non-empty if, and only if, (a) $I C_{1}$ is decreasing and convex in $\varphi$, (b) $I C_{2}$ is increasing and convex in $\varphi$, (c) $I C_{2}(\varphi=0)<I C_{3}(\varphi=0)$, and (d) $0 \leq \varphi_{1}<1$.

(i.a) Observing that $d I C_{1} / d \varphi=-\left(U_{i}(Y-p)-U_{i}(Y-p-R)\right) / \varphi^{2}<0$ and $d^{2} I C_{1} / d \varphi^{2}=$ $2\left(U_{i}(Y-p)-U_{i}(Y-p-R)\right) / \varphi^{3}>0$ establishes that $I C_{1}$ is decreasing and convex in $\varphi$. (i.b) Note that $d I C_{2} / d \varphi=\left(U_{i}(Y)-U_{i}(Y-p)\right) /(1-\varphi)^{2}>0$ and $d^{2} I C_{2} / d \varphi^{2}=2\left(U_{i}(Y)-\right.$ $\left.U_{i}(Y-p)\right) /(1-\varphi)^{3}>0$, which implies that $I C_{2}$ is increasing and convex in $\varphi$.

(i.c) Observe that $I C_{3}(\varphi=0)=U_{i}(Y)-U_{i}(Y-p-R)$, and $I C_{2}(\varphi=0)=U_{i}(Y)-$ $U_{i}(Y-p)$. Hence, because $R>0$ we have that $I C_{2}(\varphi=0)<I C_{3}(\varphi=0)$.

(i.d) In $E\left(\varphi_{1}\right)$ in Figure 2 we have that $I C_{1}=I C_{2}=I C_{3}$. Plug $s=I C_{3}(\varphi=0)$ into $I C_{1}$ or $I C_{2}$ to obtain $\varphi_{1}=\left(U_{i}(Y-p)-U_{i}(Y-p-R)\right) /\left(U_{i}(Y)-U_{i}(Y-p-R)\right)<1$.

(ii) $\xi_{1}$ is non-empty if, and only if, (a) (i.a) holds, (b) (i.b holds), and (c) $\forall s>I C_{3}(\varphi=$ $0): \varphi_{1}(s)<\varphi_{2}(s)$ with $\varphi_{i}(s)$ implicitly defined by $I C_{i}$.

(ii.c) From $I C_{1}$ follows $\varphi_{1}(s)=\left[U_{i}(Y-p)-U_{i}(Y-p-R)\right] / s ; I C_{2}$ implies $\varphi_{2}(s)=\left[U_{i}(Y-\right.$ $\left.p)+s-U_{i}(Y)\right] / s$. It follows that $\varphi_{1}(s)<\varphi_{2}(s)$ if, and only if, $U_{i}(Y-p-R)+s>U_{i}(Y)$, or $s>I C_{3}(\varphi=0)$.

\subsection{Proof of Theorem 2}

First recall that $U_{i}^{\prime}(Y-p-R)>U_{i}^{\prime}(Y-p)>U_{i}^{\prime}(Y)>0$. Second, note that $d I C_{1} / d p=$ $\left(-U_{i}^{\prime}(Y-p)+U_{i}^{\prime}(Y-p-R)\right) / \varphi>0$; in Figure 2 the $I C_{1}$-curve shifts upward if $p$ increases, $d I C_{2} / d p=\left(U_{i}^{\prime}(Y)+U_{i}^{\prime}(Y-p)\right) /(1-\varphi)>0$; the $I C_{2}$-curve shifts upward if $p$ increases, and $d I C_{3} / d p=U_{i}^{\prime}(Y)+U_{i}^{\prime}(Y-p-R)>0$; the $I C_{3}$-curve shifts upward as $p$ increases. Hence, the sign of $d \xi_{2} / d p$ is undetermined. Therefore, the sign of $d\left(\Pi^{I N}-\Pi^{N I}\right) / d p=$ $\xi_{2}+p d \xi_{2} / d p$ is not determined. 